\title{
Conversion of paroxysmal atrial fibrillation to sinus rhythm by intravenous pirmenol A placebo controlled study
}

\author{
L K TOIVONEN, M S NIEMINEN, V MANNINEN, M H FRICK \\ From the First Department of Medicine, University Central Hospital, Helsinki, Finland
}

SUMMARY The efficacy of pirmenol (a class I antiarrhythmic agent) as a converter of paroxysmal atrial fibrillation was investigated. Forty patients without congestive heart failure or a history of sinus node disorder were randomly allocated to receive either intravenous pirmenol (50-100 $\mathrm{mg}$ ) or placebo in a double blind trial. In 12 of 20 patients sinus rhythm was restored 2-16 minutes after pirmenol, and in 3 of 20 patients in the control group it returned within one hour. A nodal escape rhythm was seen during sinus slowing in one patient, but in other patients there was no sinus arrest, atrioventricular conduction disturbance, or hypotension. The ventricular rate was slightly increased in patients in whom sinus rhythm was not restored by pirmenol. The results indicate that pirmenol has an antifibrillatory effect on the atria. Sinus rhythm was restored rapidly after intravenous administration. It was well tolerated in patients with atrial fibrillation of recent onset.

Pirmenol has class I antiarrhythmic effects in Purkinje fibres. ${ }^{1}$ It suppresses premature ventricular complexes in patients ${ }^{23}$ and terminates paroxysmal supraventricular tachycardia. ${ }^{4}$ Depression of the fast inward current and a considerable increase in the duration of action potential in the rabbit atria have been reported, ${ }^{5}$ which might suggest an antifibrillatory effect on the atria. Pirmenol converted atrial tachycardia and fibrillation to sinus rhythm in dogs. ${ }^{6}$

The present randomised double blind study was undertaken to examine the efficacy of intravenous pirmenol in the acute treatment of paroxysmal atrial fibrillation.

\section{Patients and methods}

Forty patients admitted to a hospital emergency department with atrial fibrillation of recent onset $(\leqslant 48$ hours) participated in the study. Patients known or suspected to have a sinus node or atrioventricular

Requests for reprints to Dr Lauri K Toivonen, First Department of Medicine, Helsinki University Central Hospital, SF-00290 Helsinki 29, Finland.

Accepted for publication 30 September 1985 conduction disorder, acute myocardial infarction, or other severe illness, or congestive heart failure leading to interstitial extravasation shown by chest radiography were excluded. Patients who had taken digitalis or beta blocking agents $\geqslant 3$ hours before the study were included, but those patients on other antiarrhythmic agents were excluded. The appearance of symptoms was taken to indicate time of onset of fibrillation.

The patients were observed over 30 minutes for clinical evaluation and to allow their condition to stabilise. They were observed for 60 minutes after administration of pirmenol or placebo. A two lead electrocardiogram with a time track was continuously recorded at a paper speed of $50 \mathrm{~mm} / \mathrm{s}$ for analysis of the rhythm, heart rate, and electrocardiographic intervals. Brachial cuff blood pressure was measured every five minutes. Patients were randomly allocated to receive either pirmenol or placebo (20 patients each) in a double blind trial. Pirmenol (a $50 \mathrm{mg}$ bolus in $5 \mathrm{ml}$ of physiological saline) or $5 \mathrm{ml}$ of physiological saline were injected over 2 minutes and the dose was repeated after 10 minutes if sinus rhythm had not returned. Blood samples for the determination of plasma concentrations of pirmenol were drawn five minutes after the injections and at the end of the 60 minute observation period. Chest 
radiographs and $M$ mode echocardiography for determination of left atrial end systolic diameter and left ventricular dimensions according to European standards ${ }^{7}$ were obtained when in sinus rhythm. Pirmenol concentrations were measured by high performance liquid chromatography. ${ }^{8}$

\section{STATISTICAL ANALYSIS}

Analysis of variance was used to examine the significance of serial changes. We used Student's $t$ tests for continuous variables and Fisher's exact test for discrete variables to compare differences between the treatment groups and between converters and non-converters. We used the Mann-Whitney rank sum test to examine differences in duration of fibrillation. Differences of $p<0.05$ were regarded as statistically significant.

\section{Results}

Age, left atrial and ventricular echocardiographic diameter, radiological heart volume, initial heart rate, duration of fibrillation, and use of digitalis and beta blockers were similar in the groups given active drug or placebo. Because there was a slight decrease in diastolic blood pressure $(p<0.05)$ and heart rate $(p<0.0001)$ in the 30 minute period of baseline observation, we used only the values obtained during the last 15 minutes as the basis for the comparison of responses.

\section{EFFECT ON RHYTHM}

Sinus rhythm was restored in $12(60 \%)$ of 20 patients on pirmenol and in three (15\%) of 20 patients given placebo $(p<0.01)$. Conversion occurred 2-16 minutes after the first bolus of the active drug, but conversion times were randomly distributed in the placebo group (Figure). Sinus rhythm appeared after $50 \mathrm{mg}$ of pirmenol in seven patients and after a total dose of $100 \mathrm{mg}$ in five patients.

A nodal rhythm at a rate of 60 beats per minute appeared for 15 seconds after the first three sinus beats in one patient. Bradycardia or conduction disorders did not occur and there were no sinus arrests or escape rhythms in other patients. One patient who received a placebo injection developed nonsustained ventricular tachycardia, but none of the pirmenol group did so.

Fibrillation before treatment tended to last longer in non-converters than in converters $(0.05<p<0.1$; Table 1). More patients in the converter group than the non-converter group had used beta blockers $(7 / 12$ vs $1 / 8 ; p=0.07)$. No significant differences were found in any of the other baseline characteristics (Table 1).

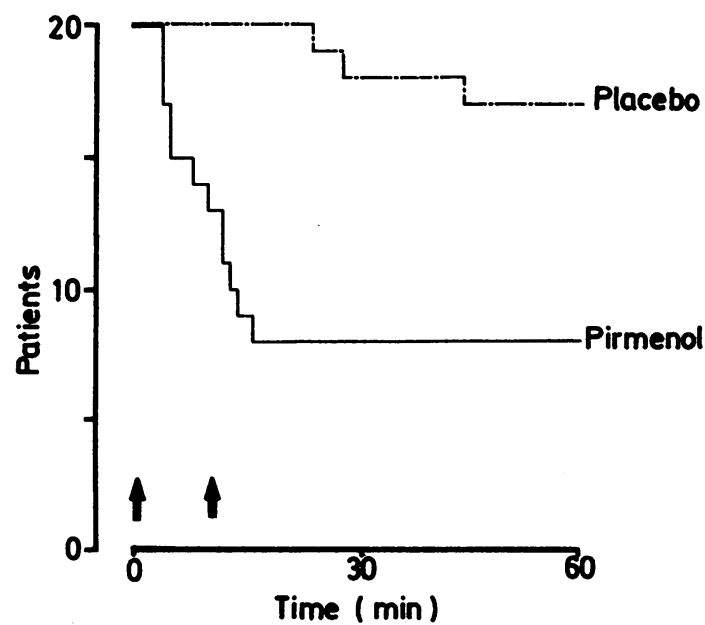

Figure Conversion of atrial fibrillation to sinus rhythm in the pirmenol and placebo groups. Vertical line shows patients remaining in atrial fibrillation. The injection times are indicated.

Table 1 Patient characteristics in the pirmenol group (mean (SD))

\begin{tabular}{|c|c|c|}
\hline & $\begin{array}{l}\text { Converters } \\
(n=12)\end{array}$ & $\begin{array}{l}\text { Non-converters } \\
(n=8)\end{array}$ \\
\hline Age (years) & $51(19)$ & $49(10)$ \\
\hline $\begin{array}{l}\text { Radiological heart volume } \\
\left(\mathrm{mm} / \mathrm{m}^{2}\right)\end{array}$ & & $520(180)$ \\
\hline $\begin{array}{l}\text { Initial heart rate } \\
\text { (beats/minute) }\end{array}$ & $115(19)$ & $99(24)$ \\
\hline $\begin{array}{l}\text { Left ventricular end diastolic } \\
\text { diameter (mm) } \\
\text { Left atrial diameter (mm) }\end{array}$ & $\begin{array}{l}51(5) \\
31(6)\end{array}$ & $\begin{array}{l}49(8) \\
34(6)\end{array}$ \\
\hline $\begin{array}{l}\text { Left ventricular rractional } \\
\text { shortening } \\
\text { Duration of atrial }\end{array}$ & $0.32(0.07)$ & $0.33(0.08)$ \\
\hline $\begin{array}{l}\text { fibrillation }(\mathrm{h}) \\
\text { Serum potassium ion }\end{array}$ & $8(7)$ & $18(14)$ \\
\hline $\begin{array}{l}\text { concentration on } \\
\text { admission (mmol/1) } \\
\text { Heart disease }(\mathbf{n}) \\
\text { Previously documented }\end{array}$ & $\begin{array}{l}3 \cdot 8(0 \cdot 2) \\
6\end{array}$ & $\begin{array}{l}4 \cdot 1(0 \cdot 2) \\
4\end{array}$ \\
\hline $\begin{array}{l}\text { atrial fibrillation (n) } \\
\text { History of high alcohol }\end{array}$ & 8 & 6 \\
\hline $\begin{array}{l}\text { consumption (n) } \\
\text { Digitalis used (n) } \\
\text { Beta blockers used (n) }\end{array}$ & $\begin{array}{l}5 \\
3 \\
7\end{array}$ & $\begin{array}{l}1 \\
2 \\
1\end{array}$ \\
\hline
\end{tabular}

*Coronary artery disease (4 patients), cardiomyopathy (2), hypertensive heart disease (3), atrial septal defect (1).

\section{RESPONSES IN HEART RATE AND BLOOD PRESSURE}

Ventricular rate increased in eight non-converters by a mean of 19 beats/minute five minutes after the second bolus of pirmenol. The use of beta blocking agents influenced the changes in heart rate. The mean heart rate before conversion or after the second bolus in eight patients who took beta blockers did not increase, whereas in 12 patients who were not on beta 
blockers the mean increase was 17 beats/minute (Table 2). Use of digitalis did not influence the change in heart rate in patients on pirmenol.

There were no significant drug induced changes in systolic or diastolic blood pressure in the converter and non-converter groups nor in those patients who used a beta blocking agent. The lowest systolic blood pressure recorded in any patient was $104 \mathrm{~mm} \mathrm{Hg}$. There were no significant changes in the blood pressure or heart rate in the placebo group.

\section{ELECTROCARDIOGRAPHIC INTERVALS AND}

PLASMA CONCENTRATIONS OF PIRMENOL

There were mean increases in QRS duration and QT interval of $12 \mathrm{~ms}(p<0.01)$ and $33 \mathrm{~ms}(p<0.001)$ respectively 15 minutes after the first injection. The longest uncorrected and corrected (Bazett's formula) QT intervals in any patient were $440 \mathrm{~ms}$ and $490 \mathrm{~ms}$ respectively. No bundle branch block appeared. The mean (SD) plasma concentration of pirmenol five minutes after the first bolus was $1.3(0.5) \mathrm{mg} / \mathrm{litre}$. In patients who received a total dose of $100 \mathrm{mg}$, the concentration was $2.1(0.8) \mathrm{mg} /$ litre five minutes after the second bolus and $1 \cdot 1(0 \cdot 3) \mathrm{mg} /$ litre at the end of the 60 minute observation period.

No patient experienced any side effects and none had any chest pain or increased dyspnoea. Sinus rhythm was later achieved in all patients after a drug induced or electrical conversion.

\section{Discussion}

This is the first report of the effects of pirmenol in paroxysmal atrial fibrillation. Other antiarrhythmic drugs have been given intravenously to convert nonestablished atrial fibrillation. Halpern et al showed that intravenous procainamide restored sinus rhythm in nine of 21 patients $(43 \%)^{9}$ and Fenster et al reported that procainamide restored sinus rhythm in $58 \%$ of patients with atrial fibrillation. ${ }^{10}$ In a study by Camm et al disopyramide terminated atrial fibrillation in 10 of 14 subjects $(71 \%){ }^{11} \mathrm{~A}$ single bolus of intravenous amiodarone restored sinus rhythm in $46 \%$ of patients in 30 minutes. $^{12}$
Intravenous flecainide converted atrial fibrillation to sinus rhythm in 14 of 39 patients within 15 minutes. ${ }^{13}$ Verapamil was successful in $8-15 \%$ of patients. ${ }^{14-16}$

Duration of fibrillation ${ }^{10}$ and the size of the left atrium ${ }^{917}$ influence the success of conversion. All the previously mentioned studies were largely performed in subjects with non-established paroxysmal or acute atrial fibrillation. ${ }^{9-16}$ Although the duration of fibrillation varied between studies, making comparison of the therapeutic effects difficult, fibrillation had not lasted more than one day in most patients. The success rate $(60 \%)$ of pirmenol resembles that of procainamide disopyramide, and amiodarone for short term intravenous use. All of these agents restore sinus rhythm rapidly.

Pirmenol increases the effective refractory period of the atria in man (unpublished). Increased refractoriness could result either from depression of the fast response channel or from prolongation of the action potential, both of which effects have been observed in rabbit atria. ${ }^{5}$ A lengthening of the atrial effective refractory period theoretically reduces the number of disorganised activation wave fronts circulating in the fibrillating atria. ${ }^{18}$ Defibrillation may be the result of the increased probability of a conduction block with extinction of re-entry due to prolonged refractoriness. Furthermore, experiments in rabbits indicate that synchronisation of atrial activation wave fronts or reduction in their number may enhance the effective conduction of the atrioventricular node and reduce the degree of concealed conduction in the atrioventricular node and hence increase the transmission of impulses to the ventricles. ${ }^{1920}$ The anticholinergic effect of pirmenol ${ }^{21}$ probably also contributes to the increase in ventricular rate during atrial fibrillation.

A higher proportion of patients on beta blockers achieved sinus rhythm ( $7 / 8$ vs $5 / 12 ; p=0.07)$, and there was no increase in heart rate in those patients who were on beta blockers. Whether beta blocking agents were causally related to the success of conversion by pirmenol cannot be definitely established. It is unlikely that their use merely selected those

Table 2 Heart rate responses (beats/minute) in patients in relation to conversion of atrial fibrillation and use of beta blockers. Values are mean (SD) at baseline and before termination of fibrillation or five minutes after the last bolus

\begin{tabular}{|c|c|c|c|c|c|}
\hline & \multirow[t]{2}{*}{ No } & \multirow[t]{2}{*}{ Baseline } & \multirow[t]{2}{*}{ Pirmenol } & \multicolumn{2}{|c|}{$p$ value for } \\
\hline & & & & Change & $\begin{array}{l}\text { Interaction between } \\
\text { group and change }\end{array}$ \\
\hline Converters & 12 & $111(20)$ & $116(18)$ & NS & $<0.05$ \\
\hline $\begin{array}{l}\text { Non-converters } \\
\text { Beta blocker }\end{array}$ & $\begin{array}{l}8 \\
8\end{array}$ & $\begin{array}{r}94(21) \\
102(26)\end{array}$ & $\begin{array}{l}113(19) \\
103(18)\end{array}$ & $\begin{array}{l}<0.01 \\
\text { NS }\end{array}$ & $<0.05$ \\
\hline No beta blocker & 12 & $106(20)$ & $122(14)$ & $<0.01$ & \\
\hline
\end{tabular}


patients with a greater chance of conversion, because left atrial diameter or duration of fibrillation were no more favourable in those on beta blockers. Also, six of the eight patients had been on long term beta blockers treatment, and this indicates that these drugs were unable to prevent the paroxysm. Similar synergism between beta blockers and quinidine in atrial fibrillation has been suspected. ${ }^{22}$

The dosages of pirmenol tested and plasma concentrations obtained paralleled those which are effective in other arrhythmias. Similar doses $(50 \mathrm{mg})$ given intravenously once or twice terminated paroxysmal supraventricular tachycardia, ${ }^{4}$ and single short infusions of up to $150 \mathrm{mg}$ abolished premature ventricular complexes. ${ }^{2}$

Rapid conversion of atrial fibrillation of recent onset by intravenous injection of a drug may avoid the need for electrical cardioversion and shorten hospital stay. A fall in blood pressure and depression of the sinus node and atrioventricular conduction system are potential adverse reactions of intravenous administration of drugs for conversion of atrial fibrillation. ${ }^{9-1114}$ Quinidine-like class I antiarrhythmics may also increase ventricular rate. ${ }^{11}$ These untoward effects have prevented the use of intravenous conversion as a routine treatment. In the present study, from which patients with advanced cardiac diseases were excluded, restoration of sinus rhythm was uncomplicated except for a short period of nodal rhythm in one patient. Although the full electrophysiological effects of pirmenol are not known, by analogy with other fast inward current inhibitors ${ }^{23-25}$ it is likely to depress impulse formation and conduction when it is used to treat arrhythmias associated with sinus and atrioventricular nodal disorders. None of our patients had a hypotensive reaction. Pirmenol is known to increase blood pressure slightly and has only a slight myocardial depressant effect. ${ }^{26}$

In conclusion, pirmenol has an antifibrillatory effect in the atria. Its efficacy seems comparable to that of the agents presently available for rapid conversion of atrial fibrillation. It is well tolerated by patients without congestive heart failure or a diseased sinus node.

\section{References}

1 Reder RF, Danilo P, Rosen MR. Effects of pirmenol $\mathrm{HCl}$ on electrophysiologic properties of cardiac Purkinje fibers. Eur $\mathcal{F}$ Pharmacol 1980; 61: 321-33.

2 Hammill SG, Shand DG, Routledge PA, Hindman MC, Baker JT, Pritchett ELC. Pirmenol, a new antiarrhythmic agent: initial study of efficacy, safety and pharmacokinetics. Circulation 1982; 65: 369-74.

3 Anderson JL, Lutz JR, Nappi JM. Pirmenol for control of ventricular arrhythmias: oral dose-ranging and short-term maintenance study. $A m \mathcal{F}$ Cardiol 1984; 53: 522-7

4 Toivonen LK, Nieminen MS, Manninen V, Frick MH. Pirmenol in termination of paroxysmal supraventicular tachycardia [Abstract]. Ann Clin Res 1985; 17: 165-6.

5 Dukes ID, Vaughan Williams EM, Dennis PD. Electrophysiological and cardiovascular effects of pirmenol, a new class 1 antiarrhythmic drug. $f$ Cardiovasc Pharmacol (in press).

6 Steffe TJ, Mertz TE, Hastings SG, Potoczak RE, Kaplan HR. CI-845 (pirmenol hydrochloride): a new orally effective long-acting antiarrhythmic agent. f Pharmacol Exp Ther 1980; 214: 50-7.

7 Roelant J, Gibson DG. Recommendations for standardization of measurements for M-mode echocardiography. Eur Heart $\mathcal{F}$ 1980; 1: 375-8

8 Shand DG, Verghese C, Barchowsky A, Hammill SC, Pritchett ELC. High performance liquid chromatography analysis of a new antiarrhythmic drug, pirmenol, in biological fluids. $\mathcal{F}$ Chromatogr 1981; 224: 343-7.

9 Halpern SW, Ellrodt G, Singh BN, Mandel WJ. Efficacy of intravenous procainamide infusion in converting atrial fibrillation to sinus rhythm. Relation to left atrial size. Br Heart $\mathcal{F}$ 1980; 44: 589-95.

10 Fenster PE, Comess KA, Marsh R, Katzenberg C, Hager WD. Conversion of atrial fibrillation to sinus rhythm by acute intravenous procainamide infusion. Am Heart f 1983; 106: 501-4.

11 Camm J, Ward D, Spurrell RAJ. The effect of intravenous disopyramide phosphate on recurrent paroxysmal tachycardias. Br $\mathcal{F}$ Clin Pharmacol 1979; 8: 441-9.

12 Strasberg B, Arditti A, Sclarovsky S, Lewin RF, Buimovici B, Agmon J. Efficacy of intravenous amiodarone in the management of paroxysmal or new atrial fibrillation with fast ventricular response. Int $\mathcal{f}$ Cardiol 1985; 7: 47-55.

13 Goy J-J, Grbig M, Hurni M, et al. Conversion of supraventricular arrhythmias to sinus rhythm using flecainide. Eur Heart $\mathcal{F}$ 1985; 6: 518-24.

14 Heng MK, Singh BN, Roche AHG, Norris RN, Mercer CJ. Effects of intravenous verapamil on cardiac arrhythmias and on the electrocardiogram. Am Heart $\mathcal{f}$ 1975; 90: 487-98.

15 Waxman HL, Myerburg RJ, Appel R, Sung RJ. Verapamil for control of ventricular rate in paroxysmal supraventricular tachycardia and atrial fibrillation or flutter. Ann Intern Med 1981; 94: 1-6.

16 Aronow WS, Landa D, Placencia G, Wong $R$, Karlsberg RP, Ferling J. Verapamil in atrial fibrillation and atrial flutter. Clin Pharmacol Ther 1979; 26: 578-83.

17 Henry WL, Morganroth J, Pearlman AS, et al. Relation between echocardiographically determined left atrial size and atrial fibrillation. Circulation 1976; 53: 273-9.

18 Allessie MA, Lammers W, Smeets J, Bonke F, Hollen $\mathrm{J}$. Total mapping of atrial excitation during acetylcholine-induced atrial flutter and fibrillation in the isolated canine heart. In: Kulbertus $\mathrm{HE}$, Olsson SB, Schlepper M, eds. Atrial fibrillation. Mölndal, Sweden: AB Hässle, 1980: 44-59. 
19 Janse MJ. Influence of the direction of the atrial wave front on A-V nodal transmission in isolated hearts of rabbits. Circ Res 1969; 25: 439-49.

20 Mazgalew T, Dreifus LS, Bianchi J, Michelson EL. Atrioventricular nodal conduction during atrial fibrillation in rabbit heart. Am $\mathcal{f}$ Physiol 1982; 243: H754-60.

21 Kaplan HR, Mertz TE, Steffe TJ, Toole JG. Pirmenol. In: Scriabine A, ed. New drugs annual: cardiovascular drugs volume 1. New York: Raven Press, 1983:133-50.

22 Stern S. Treatment and prevention of cardiac arrhythmias with propranolol and quinidine. Br Heart $\mathcal{F} 1971$; 33: 522-5.

23 Goldberg D, Reiffel JA, Davis JC, Gang E, Livelli F,
Bigger JT. Electrophysiologic effects of procainamide on sinus function in patients with and without sinus node disorder. Am Heart f 1982; 103: 75-9.

24 Tsuchioka J, Mitsuda H, Eno S, et al. Electrophysiological effects of disopyramide phosphate in patients with sinus node dysfunction. Fpn Circ $\mathcal{F}$ 1982; 46: 693-700.

25 Dhingra RC, Deedwania PC, Cummings JM, et al. Electrophysiologic effects of lidocaine on sinus node $\mathrm{v}$ and atrium in patients with and without sinoatrial dysfunction. Circulation 1978; 57: 448-54.

26 Phillips HR, Stack RS, Davis DD, et al. Hemodynamic effects of the antiarrhythmic drug, pirmenol. Clin Pharmacol Ther 1982; 32: 235-9. 